\title{
Coronary artery conundrum: A single coronary artery with origin of the right coronary artery from the distal left circumflex artery
}

\author{
Michael A. DiPietro, George Stoupakis
}

\begin{abstract}
Introduction: Single coronary artery with an anomalous origin of the right coronary artery arising from the distal portion of the left circumflex artery is a very rare angiographic finding. The incidence has been reported as $0.014-0.066 \%$ in the general population. Case Report: An 81-year-old female who presented with an acute non-ST segment elevation myocardial infarction due to a coronary lesion in the first obtuse marginal branch, but who surprisingly was found to have this rare congenital coronary anomaly. Coronary angiography in this patient revealed a single coronary artery arising from the left coronary sinus. The left anterior descending and the left circumflex arteries were in normal position with a significant stenosis in the first obtuse marginal branch. The left circumflex artery was the dominant vessel that coursed beyond the left atrio-ventricular groove, giving rise to a large branch that traversed the territory normally occupied by the right coronary artery. This rare coronary anomaly was not the cause of this patient's angina as she presented with
\end{abstract}

Michael A. DiPietro1, George Stoupakis²

Affiliations: ${ }^{1} \mathrm{MS}-\mathrm{IV}$, St. George's University School of Medicine, Grenada, West Indies; ${ }^{2 M D}$, FACC, Department of Cardiology, Hackensack University Medical Center, Hackensack, New Jersey.

Corresponding Author: George Stoupakis, MD, Department of Cardiology, Hackensack University Medical Center, 30 Prospect Avenue, Hackensack, NJ 07601; Email: George. stoupakis@hackensackmeridian.org

Received: 22 February 2018

Accepted: 05 March 2018

Published: 25 April 2018 an occlusive lesion in the first obtuse marginal branch. Conclusion: Ischemia related to single coronary artery are reported, however, most cases are asymptomatic in the absence of an obstructive lesion.

Keywords: Anomalous right coronary artery, Coronary artery anomalies, Coronary angiography, Myocardial infarction, Single coronary artery

\section{How to cite this article}

DiPietro MA, Stoupakis G. Coronary artery conundrum: A single coronary artery with origin of the right coronary artery from the distal left circumflex artery. Int J Case Rep Images 2018;9:100909Z01MD2018.

Article ID: 100909Z01MD2018

$* * * * * * * * *$

doi: 10.5348/100909Z01MD2018CR

\section{INTRODUCTION}

Coronary artery anomalies are defined as a coronary pattern or feature that is encountered in less than $1 \%$ of the general population [1]. Single coronary artery (SCA) is very rare among the types of coronary artery anomalies, and when present, is commonly associated with other congenital cardiovascular anomalies such as transposition of the great vessels, tetralogy of Fallot, coronary fistulas, and bicuspid aortic valves [2]. The incidence of all types of single coronary artery was found to be $0.014-0.066 \%$ in the general population, with the right coronary artery (RCA) arising from the distal left circumflex (LCX) being an especially rare variant [3]. 


\section{EDORIUM Journals}

Int J Case Rep Images 2018;9:100909Z01MD2018.

www.ijcasereportsandimages.com

\section{CASE REPORT}

An 81-year-old hypertensive, nonsmoking female who presented to our institution with typical chest pressure radiating to the arm and jaw. A baseline electrocardiogram revealed sinus bradycardia with ST segment flattening in the lateral leads but no significant ischemic changes (Figure 1). She was found to rule in for an acute non-ST segment elevation myocardial infarction (NSTEMI) with an elevation in cardiac Troponin I. An echocardiogram revealed normal biventricular function and no regional wall motion abnormalities. The patient underwent a coronary angiogram for the evaluation of CAD in view of the positive enzyme elevations. Initially, the right coronary artery was attempted to be cannulated with a $6 \mathrm{~F}$ Judkins Right 4 catheter; however, the ostium could not be found for cannulation. This made us suspect a possible anomalous right coronary artery arising from the left coronary sinus. However, cannulation of the left coronary ostium using a $6 \mathrm{~F}$ Judkins Left 4 catheter revealed a single coronary artery that divided into the left anterior descending (LAD) and the left circumflex artery (Figure 2). The LCX artery was the dominant vessel that coursed beyond the left atrio-ventricular groove up to the level normally occupied by the right coronary artery (Figure 3). An aortic root angiogram was performed and excluded an abnormal take-off of the RCA. The patient was found to have a $90 \%$ stenosis of the first obtuse marginal branch that arose from the native LCX. She underwent successful Percutaneous Coronary Angioplasty (PTCA) with a synergy 3.0x24 mm drug eluting stent (Boston Scientific, Marlborough, Massachusetts). After PTCA, the patient was started on aspirin, clopidogrel, atorvastatin, and metoprolol and was discharged without any significant complications.

\section{DISCUSSION}

A single coronary artery is defined as being present when one artery arises from the aortic trunk by a single coronary ostium and supplies the entire heart regardless

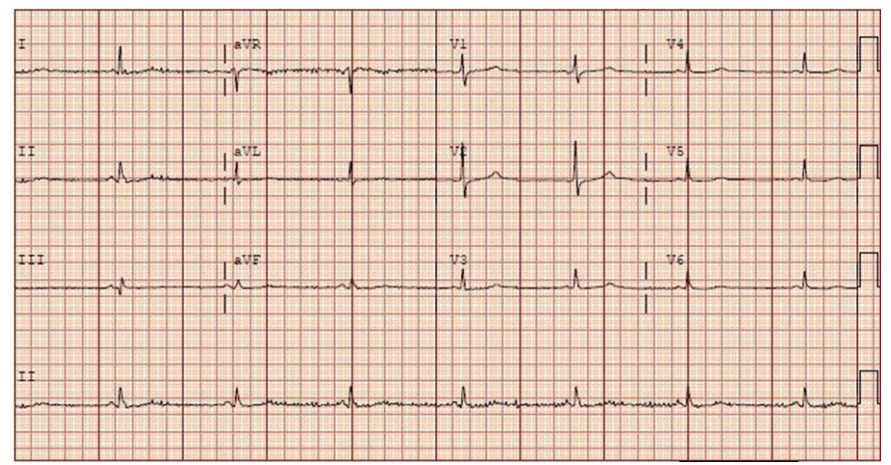

Figure 1: Baseline 12 lead electrocardiogram showing sinus bradycardia with ST segment flattening in the anterior leads (V1-V6).

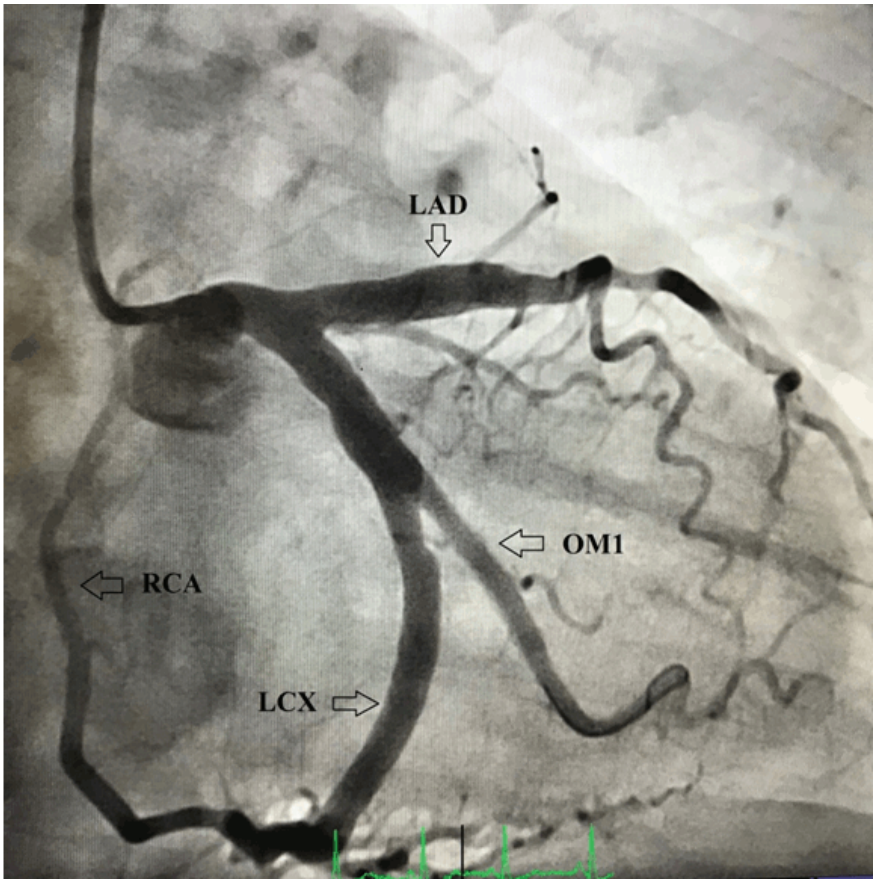

Figure 2: Coronary angiogram showing the single coronary artery bifurcating into the left anterior descending (LAD) and left circumflex (LCX) artery with right coronary artery (RCA) arising from the distal LCX and coursing beyond the atrioventricular groove. The first obtuse marginal artery (OM1), post PTCA.

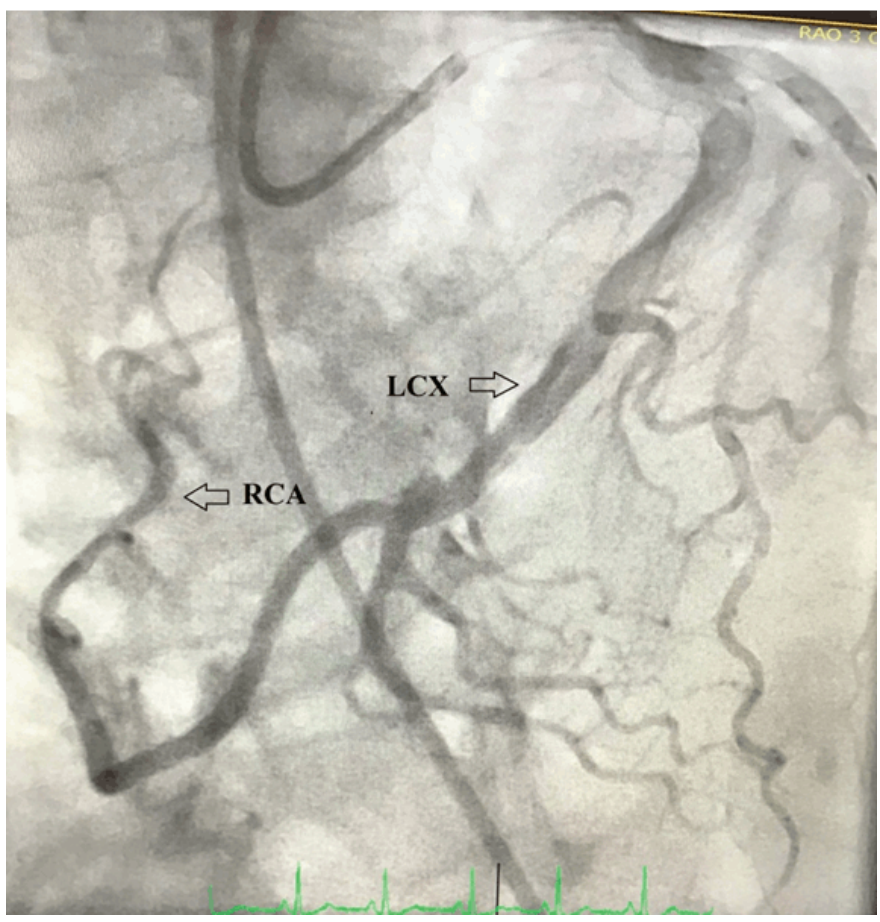

Figure 3: Coronary angiogram showing the dominant left circumflex artery (LCX) with right coronary artery (RCA) originating from the distal portion of the LCX. 


\section{EDORIUM Journals}

of its distribution [4]. The first classification system for single coronary artery was proposed by Smith [5] in 1950 [6]. He put forth the idea of three categories according to the distribution of the single coronary artery. The first type included the cases in which the single vessel followed the course of only the normal right or left coronary artery. The second type included the cases in which the single vessel arose from a single ostium, but immediately divided and the subsequent branches were present in the distribution of both the right and left coronary artery. The third type comprised of cases in which the vessel distribution was atypical, and could not be compared to the distribution of a normal left or right coronary artery.

The classification system widely used today was proposed by Lipton et al [4] in 1979, and further modified by Yamanaka and Hobbs [7] in 1990. The single coronary artery is first categorized according to its site of origin, garnering the label " $\mathrm{R}$ " or " $\mathrm{L}$ " depending upon whether the ostium is located in the right or left sinus of Valsalva, respectively. The anomalous vessel is then further classified according to its anatomical distribution, designated Group I, II, or III. The vessels classified as Group I have an anatomical course of either a normal right or left coronary artery. A Group II pattern is seen when the single artery arises from the proximal part of the normal right or left coronary artery and crosses the base of the heart before assuming the normal course of the inherent artery. Group III anomalies are those in which the left anterior descending and left circumflex arteries arise separately from the proximal part of the normal right coronary artery. Finally, the anomalous vessel is designated with a letter describing its relationship with the aorta and pulmonary artery: A (anterior to the right ventricular outflow tract), B (between the aorta and pulmonary artery), $\mathrm{P}$ (posterior to aorta), S (septal) or C (combined).

The patient in this case had a single coronary artery that arose from the left sinus of Valsalva, divided into the LAD and LCX with the distal LCX continuing and following the course of a normal RCA to the base of the heart. According to the Lipton classification system, this is an LI type anomaly, which is an especially rare coronary artery anomaly. Yamanaka and Hobbs [7] found that the incidence of LI type single coronary arteries was $0.016 \%$ in the general population, while Turkmen et al [3] found the incidence of SCA to be $0.031 \%$, with only $24 \%$ of those with SCA having an LI type.

A single coronary artery has been associated with myocardial ischemia/infarction and sudden cardiac death, with coronary artery anomalies being the second most common cause of SCD in young athletes [8]. Shirani and Roberts [9] reported that $15 \%$ of cases of single coronary artery had clinical or morphologic evidence of ischemia related directly to the coronary anomaly. In these patients, the exact mechanisms for SCD or ischemia in the absence of an atherosclerotic lesion is unknown, but several have been proposed. These include spasm of the anomalous vessel, insufficient collateral blood supply, increased blood flow resistance, an acute angle of origin of the anomalous vessel, a slit-like opening of the vessel, compression of the artery between the pulmonary and aortic trunks, and an intramural course of the vessel $[2,10]$.

While there are reports of ischemia related directly to the SCA, the majority of cases have a benign prognosis in the absence of an atherosclerotic lesion [2, 7, 10-13, 14]. Ultimately, the prognosis of an isolated SCA depends upon the extent of the underlying coronary artery stenosis, and due to the heart's dependence on a single coronary artery for circulation, it stands to reason that coronary lesions in these patients are of a more acute significance.

Given the limited number of cases of isolated SCA, a clear treatment modality has yet to be established. The treatment strategies documented in previous cases have varied based upon the patient's presenting symptoms and the extent of atherosclerotic disease within the coronary artery. Those patients with no, or mild evidence of atherosclerosis, in the absence of significant ischemia, have been managed with optimum medical therapy [11]. Successful PTCA has been documented in many cases, as has coronary artery bypass grafting in those patients who could not be effectively treated with PTCA [3, 10-15]. Those patients with evidence of ischemia in the absence of an atherosclerotic lesion should be treated with surgical correction $[3,10,13]$.

The patient in our case did not have any evidence of ischemia related directly to the single coronary artery, and the cause of her angina was secondary to an obstructive lesion in the first obtuse marginal artery. She was successfully treated with PTCA of and was started on aspirin, clopidogrel, atorvastatin, and metoprolol prior to discharge.

\section{CONCLUSION}

Although there have been reports of ischemia related directly to a single coronary artery, the majority of cases are asymptomatic in the absence of an obstructive atherosclerotic lesion. Recognition of this rare coronary artery anomaly is of extreme importance whenever one encounters difficulty identifying both coronary ostium at the time of cardiac catheterization.

\section{REFERENCES}

1. Villa AD, Sammut E, Nair A, Rajani R, Bonamini R, Chiribiri A. Coronary artery anomalies overview: The normal and the abnormal. World J Radiol 2016 Jun 28;8(6):537-55.

2. Ma SH, Kim DH, Hur JY, et al. Right ventricular myocardial infarction due to right coronary artery total occlusion originating from the distal left circumflex artery. Korean Circ J 2012 Aug;42(8):565-7.

3. Turkmen S, Yolcu M, Sertcelik A, Ipek E, Dokumaci B, Batyraliev T. Single coronary artery incidence in 
215,140 patients undergoing coronary angiography. Folia Morphol (Warsz) 2014 Nov;73(4):469-74.

4. Lipton MJ, Barry WH, Obrez I, Silverman JF, Wexler L. Isolated single coronary artery: Diagnosis, angiographic classification, and clinical significance. Radiology 1979 Jan;130(1):39-47.

5. Smith JC. Review of single coronary artery with report of 2 cases. Circulation 1950 May;1(5):1168-75.

6. Ogden JA, Goodyer AV. Patterns of distribution of the single coronary artery. Yale J Biol Med 1970 Aug;43(1):11-21.

7. Yamanaka O, Hobbs RE. Coronary artery anomalies in 126,595 patients undergoing coronary arteriography. Cathet Cardiovasc Diagn 1990 Sep;21(1):28-40.

8. Maron BJ. Sudden death in young athletes. N Engl J Med 2003 Sep 11;349(11):1064-75.

9. Shirani J, Roberts WC. Solitary coronary ostium in the aorta in the absence of other major congenital cardiovascular anomalies. J Am Coll Cardiol 1993 Jan;21(1):137-43.

10. Yurtdas M, Gülen O. Anomalous origin of the right coronary artery from the left anterior descending artery: Review of the literature. Cardiol $\mathrm{J}$ 2012;19(2):122-9.

11. Chou LP, Kao C, Lee MC, Lin SL. Right coronary artery originating from distal left circumflex artery in a patient with an unusual type of isolated single coronary artery. Jpn Heart J 2004 Mar;45(2):33742.

12. Pourafkari L, Taban M, Ghaffari S. Anomalous origin of right coronary artery from distal left circumflex artery: A case study and a review of its clinical significance. Journal of Cardiovascular and Thoracic Research 2014;6(2):127-30.

13. Pourbehi MR, Amini A, Farrokhi S. Single coronary artery with anomalous origin of the right coronary artery from the distal portion of left circumflex artery: A very rare case. J Tehran Heart Cent 2013 Jul;8(3):161-3.

14. Singh S, Sahoo SK, Tripathy MP, Jena G. Angiographic enigma: A single coronary artery with the right coronary artery originating from the distal left circumflex artery. Heart Views 2015 JulSep;16(3):104-6.
15. Chung SK, Lee SJ, Park SH, Lee SW, Shin WY, Jin DK. An extremely rare variety of anomalous coronary artery: Right coronary artery originating from the distal left circumflex artery. Korean Circ J 2010 Sep;40(9):465-7.

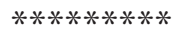

\section{Author Contributions}

Michael A. DiPietro - Substantial contributions to conception and design, Acquisition of data, Analysis and interpretation of data, Drafting the article, Final approval of the version to be published

George Stoupakis - Substantial contributions to conception and design, Analysis and interpretation of data, Revising it critically for important intellectual content, Final approval of the version to be published

\section{Guarantor of Submission}

The corresponding author is the guarantor of submission.

\section{Source of Support}

None

\section{Consent Statement}

Written informed consent was obtained from the patient for publication of this case report.

\section{Conflict of Interest}

Authors declare no conflict of interest.

\section{Copyright}

(C) 2018 Michael A. DiPietro et al. This article is distributed under the terms of Creative Commons Attribution License which permits unrestricted use, distribution and reproduction in any medium provided the original author(s) and original publisher are properly credited. Please see the copyright policy on the journal website for more information.
Access full text article on other devices

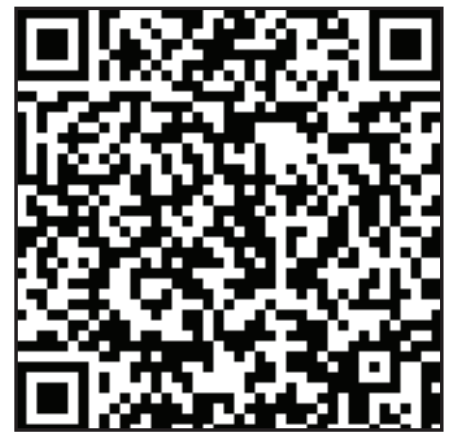

Access PDF of article on other devices

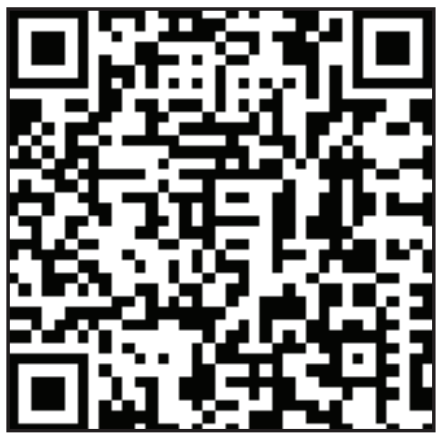

